\title{
Mental health, sexual identity, and interpersonal violence: Findings from the Australian longitudinal Women's health study
}

Laura A. Szalacha ${ }^{1 *}$ (D), Tonda L. Hughes ${ }^{2,3}$, Ruth McNair $^{4}$ and Deborah Loxton ${ }^{5,6}$

\begin{abstract}
Background: We examined the relationships among experiences of interpersonal violence, mental health, and sexual identity in a national sample of young adult women in Australia.

Methods: We used existing data from the third (2003) wave of young adult women (aged 25-30) in the Australian Longitudinal Study on Women's Health (ALSWH). We conducted bivariate analyses and fit multiple and logistic regression models to test experiences of six types of interpersonal violence (physical abuse, severe physical abuse, emotional abuse, sexual abuse, harassment, and being in a violent relationship), and the number of types of violence experienced, as predictors of mental health. We compared types and number of types of violence across sexual identity subgroups.

Results: Experiences of interpersonal violence varied significantly by sexual identity. Controlling for demographic characteristics, compared to exclusively heterosexual women, mainly heterosexual and bisexual women were significantly more likely to report physical, sexual, and emotional abuse. Mainly heterosexual and lesbian women were more likely to report severe physical abuse. Mainly heterosexual women were more than three times as likely to have been in a violent relationship in the past three years, and all three sexual minority subgroups were two to three times as likely to have experienced harassment. Bisexual women reported significantly higher levels of depression than any of the other sexual identity groups and scored lower on mental health than did exclusively heterosexual women. In linear regression models, interpersonal violence strongly predicted poorer mental health for lesbian and bisexual women. Notably, mental health indicators were similar for exclusively heterosexual and sexual minority women who did not report interpersonal violence. Experiencing multiple types of interpersonal violence was the strongest predictor of stress, anxiety and depression.
\end{abstract}

Conclusions: Interpersonal violence is a key contributor to mental health disparities, especially among women who identify as mainly heterosexual or bisexual. More research is needed that examines within-group differences to determine which subgroups are at greatest risk for various types of interpersonal violence. Such information is critical to the development of effective prevention and intervention strategies.

Keywords: Interpersonal violence, Female sexual identity, Stress, Depression, Australian longitudinal Women's health study

\footnotetext{
* Correspondence: DrLSzalacha@email.arizona.edu

${ }^{1}$ Office of Nursing Research, College of Nursing, University of Arizona,

Tucson, USA

Full list of author information is available at the end of the article
} 


\section{Background}

Violence against women is one of the least visible but most widespread forms of violence in the world. The World Health Organization has noted global epidemic rates of violence against women and highlighted the serious, longterm effects of such violence by positioning it as a leading worldwide public health issue [1]. The Australian component of the International Violence Against Women Survey found that $48 \%$ of the female population had experienced at least one incident of physical abuse in their lifetime, and $34 \%$ had experienced at least one incident of sexual violence [2]. In Victoria, Australia, intimate partner violence is the leading contributor to death, disability, and illness in women aged 15 to 44 years [3].

The relationship between violence and poor mental health is well established in the literature [4-11]. For example, in analyses of the mid-aged women in the Australian Longitudinal Study on Women's Health (ALSWH), Loxton, Schofield, and Hussain found strong and consistent relationships among domestic violence, poorer mental health, and depression [12]. In addition, results of a recent metaanalysis conducted by MacIsaac and colleagues showed a strong association between interpersonal violence and suicide among women [13]. Compared to their heterosexual counterparts, sexual minority women are at increased risk for mental health problems such as depression, anxiety disorders, and substance abuse [14-17]. One potential explanation for mental health disparities among sexual minority women is elevated rates of interpersonal violence.

In the past decade, evidence has accumulated indicating that a disproportionately high number of sexual minority women (those who do not identify as exclusively heterosexual) are victims of physical and sexual abuse $[10,11,14,18-20]$. Although the factors that account for this disparity are poorly understood, researchers have found strong associations between violence and substance abuse, depression, and anxiety among sexual minority women [10, 11, 15, 21-26].

Studies conducted in the United States that compared experiences of violence in sexual minority and heterosexual women have found compelling evidence of sexualorientation-related disparities. In one such study, Balsam, Rothblum, and Beauchaine found that lesbian, gay, and bisexual participants were more likely than their heterosexual siblings to report childhood physical abuse (CPA), childhood sexual abuse (CSA), ever being assaulted by a partner, and a history of sexual coercion or rape [19]. Similarly, Moracco found that a combined sample of lesbian and bisexual women reported significantly higher rates of physical and sexual assault by a stranger or known person than did heterosexual women [27]. In addition to the growing consensus that sexual minority women are more likely than heterosexual women to experience violence, results of recent studies suggest that rates vary, sometimes substantially, across sexual minority subgroups.

With few exceptions, most research on violence among SMW has not assessed subgroup differences $[10,11,22,28]$. Studies that examine within group differences have most often focused on comparisons between lesbian and bisexual women. For example, Balsam and colleagues compared data from bisexual and lesbian women and found that bisexuals were significantly more likely than lesbians to report sexual coercion and sexual assault in adulthood [19]. Similarly, Hughes and colleagues found that bisexual women reported significantly higher rates of CSA, CPA, partner violence, and nonpartner violence than did heterosexual women, whereas only CSA differed between lesbian and heterosexual women [22]. A focus on binary classifications of sexual identity (e.g., sexual minority vs. heterosexual, or lesbian vs. bisexual) may mask important variation across subgroups of sexual minority women. In addition, recent research has begun to document health disparities among women who identify as mainly or mostly heterosexual. For example, using data from a U.S. community-based sample, Austin and colleagues found that young women, aged 18 to 24 years, who identified as "mostly heterosexual" reported significantly higher rates of CSA than did those who identified as heterosexual [23]. Although not a study of violence, Hughes, Szalacha, and McNair found that sexual minority women in Australia who identified as mainly heterosexual were significantly more likely than exclusively heterosexual women to report at-risk drinking ( $\geq 15$ drinks per week) and binge drinking [16]. Similarly, Hughes, Wilsnack and Kristjanson found that compared with their exclusively heterosexual counterparts who identified as mostly heterosexual were 2-4 times as likely to report every substance use outcome assessed except lifetime treatment for an alcoholrelated problem [29].

In summary, most research has not assessed subgroup differences within sexual minority populations. In addition, very few studies have examined multiple types of violence or multiple mental health outcomes across sexual minority subgroups.

Therefore, using data from the Australian Longitudinal Study on Women's Health (ALSWH) we addressed the following research questions:

1. Do experiences of interpersonal violence (physical abuse, severe physical abuse, emotional abuse, sexual abuse, harassment, being in a violent relationship, and number of types of violence experienced (individual types of violence and the number of different types) vary significantly across sexual identity subgroups?; and, 
2. To what extent is the association between sexual identity and poorer mental health accounted for by experiences of interpersonal violence?

Examining differences between heterosexual and sexual minority women can improve understanding of sexual identity-related health disparities. In addition, understanding sexual minority subgroup differences can inform the development of targeted prevention and intervention strategies.

\section{Methods}

The ALSWH is a prospective study that began in 1996 with the goal of tracking the health of women in three age cohorts (18-23, 45-50, and 70-75 at baseline) for at least 20 years [30]. The study samples are drawn from the database of Medicare Australia, the universal provider of basic health insurance, which involves all people in Australia (including all citizens and permanent residents). Sampling from the population was random within each age group, with oversampling from rural and remote areas to allow for statistical comparisons of the circumstances and health of city and country participants. Mailed surveys are completed approximately every three years. Further details of the study design and methods have been reported elsewhere [30-32]. The current analyses focus on data from the third survey of the young cohort because it was the most recent survey in which sexual identity was assessed. A total of 9074 participants completed Survey 3, an estimated response rate of $64 \%$. The young women (aged 25-30) who answered the sexual identity question $(n=8850)$ serve as the analytic sample for this study.

\section{Measures}

\section{Sexual identity}

Participants were asked which of five categories best described their sexual identity: exclusively heterosexual, mainly heterosexual, bisexual, mainly lesbian, or exclusively lesbian. For the current analyses, participants who identified as mainly lesbian or exclusively lesbian were combined because of the small number of women in the mainly lesbian and exclusively lesbian groups and because of the similarity between the two groups relative to demographic characteristics and the study variables.

\section{Experiences of interpersonal violence}

The interpersonal violence questions were based on a previously existing battery of questions [33]. Participants were asked whether or not in the previous three years they had experienced the following: (1) physical abuse (e.g., pushed, grabbed, kicked, hit, shoved, slapped, shaken, restrained); (2) severe physical abuse (e.g., beaten up, thrown, choked, burnt, attacked with a fist, knife or gun);
(3) emotional abuse (e.g., called names, threatened with harm or death, humiliated, bullied, criticized, locked up/ isolated, refused access to work, medical care or money, told that their children or pets would be harmed); (4) sexual abuse (e.g., rape or attempted rape, sexual assault, forced to engage in unwanted sexual practices); and (5) harassment (e.g., stalking, loitering, interfering with property, offensive mail or telephone calls). An additional question asked whether participants "had ever been in a violent relationship with a partner or spouse" (violent relationship was not defined for survey participants). Responses to the six items were summed to create a continuous measure of interpersonal violence experiences (range 0-6).

\section{Mental health outcomes \\ Stress}

The Perceived Stress Questionnaire for Younger Women was developed specifically for the ALSWH. Studies of the younger cohort conducted by Bell and Lee [34, 35] have demonstrated that the scale is valid and reliable (e.g., Cronbach's alpha $=0.74$ ). Respondents were asked 11 questions about how stressed they have felt over the previous 12 months in relationship to several life domains, such as family of origin, relationships with partner/spouse and others, health, work/employment, study, and motherhood/children. Responses were on a 5-point Likert-type scale ranging from $0=$ not at all stressed (or not applicable) to $4=$ extremely stressed, with higher scores indicating higher levels of stress.

\section{Anxiety}

Participants were asked a single question about how often in the previous 12 months they had experienced episodes of intense anxiety (anxiety symptoms; $0=$ never to $3=$ often).

\section{Depression}

A 10-item version of the Center for Epidemiologic Studies Depression Scale (CES-D) was used to assess current (past 4 weeks) depression. The CES-D was developed specifically to identify depressive symptoms and screen for depression in non-clinical populations. Scale scores range from 0 to 30 . The 10-item version of the CES-D used in the ALSWH demonstrated good internal consistency (Cronbach's alpha $=0.80)$ and validity [36]. Responses ranged $0-10$, with higher scores indicating higher levels of depressive symptoms.

\section{Mental health index}

To assess overall mental health, we used responses to a 5 -item subscale of the well-validated Medical Outcomes 36-item Short Form Survey (SF-36) [37]. Participants were asked to "give the one answer that comes closest to 
the way you've been feeling during the past four weeks." Response options were on a 6-point Likert-type scale ranging from none of the time to all of the time. Summed scores ranged from 0 to 100, with higher scores indicating better overall mental health status (Cronbach's alpha $=0.88)$.

\section{Life satisfaction}

Respondents were asked about their satisfaction with seven areas of their life. "In general, are you satisfied with what you have achieved in your life so far" in the areas of work, career, study, family relationships, partner/ closest personal relationship, friendships, and social activities. Response options were on a 4-point Likert-type scale ranging from very dissatisfied to very satisfied, with higher scores indicating greater life satisfaction.

Copies of all of the ALSWH surveys can be found at the study website [38].

\section{Control variables}

Multivariate analyses controlled for the potential confounding effects of education, income, and region of residence. Given the narrow age range of the young cohort sample (25-30 years), age was not included as a control variable. All of the control variables were treated as categorical: education ( 1 = year 10 or less, 2 = year 12 or equivalent, 3 = Trade/Diploma, 4 = undergraduate degree, and 5 = higher university degree), annual income in Australian dollars $(1=\$ 0$ to $\$ 15,999,2=\$ 16,000-\$ 36,999$, $3=\$ 37,000-\$ 51,999,4=\$ 52,000$ or more), relationship status ( 1 = married; 2 = living in a de facto relationship; 3 = separated, divorced, or widowed; or $4=$ single), parental status $(0=$ no child, $1=$ one or more children $)$, and region of residence ( $1=$ urban, $0=\mathrm{rural} / \mathrm{remote})$.

\section{Data analysis}

We compared socio-demographic characteristics, types of interpersonal violence, and mental health outcomes across the four sexual identity groups, using contingency table analyses for the categorical variables and ANOVA and ANCOVA for the continuous variables. We fit six logistic regression models to the data to estimate the relative risk of each type of interpersonal violence based on sexual identity, controlling for residence, education, and income. We fit five linear regression models to predict mental health outcomes by sexual identity and number of types of interpersonal violence, controlling for the same demographic variables. In analyses not including residence as a predictor, the data were weighted by region. Exclusively heterosexual women served as the reference group in all comparisons of sexual identity. We report standardized beta coefficients to facilitate comparison of effect size. Data were analyzed using Stata 10 [39] with an alpha of 0.05 for all statistical tests.

\section{Results}

\section{Sample socio-demographic characteristics}

The majority of participants in the sample identified as exclusively heterosexual, $91.3 \%(n=8083)$; $6.4 \%$ identified as mainly heterosexual $(n=568), 1.1 \%$ identified as bisexual $(n=100)$, and $1.1 \%$ identified as mainly lesbian or exclusively lesbian $(n=99)$. The distributions of the socio-demographic characteristics differed significantly by sexual identity (see Table 1). Women who identified as exclusively heterosexual were proportionally more likely than those in other groups to be married (44.0\%), ${ }^{1}$ to live in rural/remote areas $(40.4 \%)$, to have children (32.8\%), and to report annual incomes of $\$ 52,000$ or more (40.4\%). Lesbian-identified women were significantly older $(M=27.5, S D=1.4)$ than each of the other three sexual identity groups $\left(\mathrm{F}_{(3,7605)}=2.98, p=.03\right)$, and were proportionally more likely to have a university or graduate degree (51.5\%).

\section{Experiences of interpersonal violence}

Both the individual types and the total number of types of interpersonal violence differed significantly by sexual identity. Women in each of the three sexual minority groups were more likely than exclusively heterosexual women to report every type of interpersonal violence (physical abuse, severe physical abuse, emotional abuse, harassment, sexual abuse, and partner violence; see Table 1). Bisexual and mainly heterosexual women were most likely to report experiencing each of the six types of interpersonal violence. Substantially fewer exclusively heterosexual women reported physical abuse (11.5\%) than did mainly heterosexual (24\%), bisexual (29\%), or lesbian (22\%) participants. Similarly, between $6.5 \%$ and $11 \%$ of the sexual minority groups reported severe physical abuse, compared with only $2.1 \%$ of exclusively heterosexual women. Bisexual participants were significantly more likely than the other three sexual identity groups to report both emotional abuse and sexual abuse. Harassment was reported by $9.7 \%$ of exclusively heterosexual, $19.5 \%$ mainly heterosexual, $25.0 \%$ bisexual, and $21.2 \%$ of lesbian participants. Similarly, $10.0 \%$ of exclusively heterosexual participants reported ever having been in a violent relationship, compared with $24.6 \%$ mainly heterosexual, $24.5 \%$ bisexual, and $14.7 \%$ lesbian participants. The number of types of interpersonal violence reported also differed by sexual identity; exclusively heterosexual women reported significantly fewer experiences $(M=.44$, $S E=.01)$ and bisexual women reported significantly more experiences $(M=1.20, S E=.09)$ than each of the other groups $(\eta=.02)\left(\mathrm{F}_{(4,8885)}=53.48, p<.001\right)$.

We fit six logistic regression models to the data to estimate the relative risk of each type interpersonal violence based on sexual identity. Results, summarized in Table 2, indicate a greater burden of interpersonal 
Table 1 ALSWH young cohort socio-demographic characteristics, violence experiences and mental health by sexual identity

\begin{tabular}{|c|c|c|c|c|c|c|}
\hline & $\begin{array}{l}\text { Exclusively Heterosexual } \\
(n=8083)\end{array}$ & $\begin{array}{l}\text { Mainly Heterosexual } \\
(n=568)\end{array}$ & $\begin{array}{l}\text { Bisexual } \\
(n=100)\end{array}$ & $\begin{array}{l}\text { Lesbian } \\
(n=99)\end{array}$ & x2 Test Statistic & $\begin{array}{l}\text { Cramer's } \\
V\end{array}$ \\
\hline & $\%$ & $\%$ & $\%$ & $\%$ & & \\
\hline \multicolumn{7}{|l|}{ Education } \\
\hline Year 10 or less & 9.9 & 10.3 & 20.6 & 5.2 & & \\
\hline Year 12 or equivalent & 19.4 & 19.4 & 19.6 & 17.5 & & \\
\hline Trade/Diploma & 26.7 & 24.8 & 26.8 & 25.8 & & \\
\hline University degree & 34.2 & 34.6 & 25.8 & 44.3 & $(d f=12)$ & $.031^{*}$ \\
\hline Graduate degree & 10.7 & 10.9 & 7.2 & 7.2 & $x^{2}=21.0^{* *}$ & \\
\hline \multicolumn{7}{|l|}{ Income (AUD) } \\
\hline 15,999 or less & 1.9 & 2.4 & 6.8 & 4.3 & & \\
\hline $16,000-36,999$ & 4.8 & 6.2 & 13.6 & 8.6 & & \\
\hline $37,000-51,999$ & 11.5 & 12.1 & 13.6 & 12.9 & $(d f=9)$ & $.036^{*}$ \\
\hline 52,000 or greater & 81.4 & 79.4 & 66.1 & 74.3 & $x^{2}=25.7^{* *}$ & \\
\hline \multicolumn{7}{|l|}{ Relationship Status } \\
\hline Single & 32.6 & 50.0 & 58.0 & 62.6 & & \\
\hline Married & 44.0 & 18.9 & 13.0 & 2.0 & & \\
\hline De facto & 19.9 & 25.4 & 20.0 & 32.3 & $(d f=9)$ & $.098^{* * *}$ \\
\hline Separated/Divorced & 3.5 & 5.7 & 9.0 & 3.0 & $x 2=255.1^{* * *}$ & \\
\hline \multicolumn{7}{|l|}{ Parental Status } \\
\hline No children & 67.2 & 73.8 & 72.0 & 93.9 & $(d f=3)$ & $.069^{* * *}$ \\
\hline 1 or more children & 32.8 & 26.2 & 28.0 & 6.1 & $x^{2}=43.2^{* * *}$ & \\
\hline \multicolumn{7}{|l|}{ Residence } \\
\hline Urban & 59.6 & 69.7 & 69.8 & 69.8 & $(d f=3)$ & $.046^{* * *}$ \\
\hline Rural/Remote & 40.4 & 30.3 & 30.2 & 30.2 & $x^{2}=29.6^{* * *}$ & \\
\hline Violence & & & & & $(d f=9)$ & \\
\hline Physical abuse & 11.50 & 24.10 & 29.00 & 22.20 & $x^{2}=110.0^{* * *}$ & $.111^{* * *}$ \\
\hline Severe physical abuse & 2.10 & 6.50 & 11.00 & 10.10 & $x^{2}=91.3^{* * *}$ & $.102^{* * *}$ \\
\hline Emotional abuse & 20.60 & 32.40 & 46.00 & 28.30 & $x^{2}=80.8^{* * *}$ & $.096^{* * *}$ \\
\hline Sexual abuse & 2.10 & 6.20 & 14.00 & 3.00 & $x^{2}=93.5^{* * *}$ & $.103^{* * *}$ \\
\hline Harassment & 9.70 & 19.50 & 25.00 & 21.20 & $x 2=88.2^{* * *}$ & $.100^{* * *}$ \\
\hline \multirow[t]{2}{*}{ Violent relationship } & 10.00 & 24.60 & 24.50 & 14.70 & $x^{2}=130.4^{* * *}$ & $.123^{* * *}$ \\
\hline & $\mathrm{M}(\mathrm{SE})$ & M (SE) & $M(S E)$ & $M(S E)$ & F-test & \\
\hline Overall number of violent experiences & $.44(.01)^{\mathrm{a}}$ & $.79(.04)$ & $1.20(.09)^{b}$ & $.89(.09)$ & $\mathrm{F}_{(4,7610)}=53.48^{* * *}$ & \\
\hline \multicolumn{7}{|l|}{ Mental Health } \\
\hline Perceived Stress & $.88 .50^{\mathrm{a}}$ & 1.10 .62 & 1.34 .69 & 1.04 .54 & $F_{(3,7587)}=53.0^{* *}$ & \\
\hline Anxiety Symptoms & $1.3 .68^{\mathrm{b}}$ & 1.5 .86 & 1.7 .99 & 1.5 .87 & $F_{(3,7587)}=23.9^{* * *}$ & \\
\hline CES-D & 6.75 .1 & 7.75 .9 & $9.55 .9^{c}$ & 7.75 .9 & $F_{(3,7487)}=14.9^{* * *}$ & \\
\hline Mental Health Index & 71.016 .7 & 66.518 .9 & $64.118 .4^{d}$ & 67.118 .8 & $\mathrm{~F}_{(3,7585)}=17.5^{* * *}$ & \\
\hline Life Satisfaction & $3.3 .42^{\mathrm{e}}$ & 3.1 .48 & 3.0 .51 & 3.2 .42 & $F_{(3,7585)}=33.6^{* * *}$ & \\
\hline
\end{tabular}

${ }^{\mathrm{a}}$ Exclusively heterosexual significantly lower than all other groups $(\eta=.021)$. ${ }^{\mathrm{b}}$ Exclusively heterosexual significantly lower thanall other groups $(\eta=.014)$. ${ }^{c}$ Bisexual significantly higher than all other groups $(\eta=.013) .{ }^{\mathrm{d}}$ Bisexual significantly lower than exclusively heterosexual $(\eta=.013) .{ }^{e}$ Exclusively heterosexual significantly higher than mainly heterosexual and bisexual $(\eta=.013)$

${ }^{*} p<.05 .{ }^{* *} p<.01 .{ }^{* * *} p<.001$ 
Table 2 Experiences of violence reported by sexual identity, controlling for socio-demographic characteristics ${ }^{a}$

\begin{tabular}{lllllll}
\hline & $\begin{array}{l}\text { Physical violence } \\
\text { AOR }(95 \% \mathrm{Cl})\end{array}$ & $\begin{array}{l}\text { Severe physical violence } \\
\text { AOR }(95 \% \mathrm{Cl})\end{array}$ & $\begin{array}{l}\text { Emotional abuse } \\
\text { AOR }(95 \% \mathrm{Cl})\end{array}$ & $\begin{array}{l}\text { Sexual abuse } \\
\text { AOR }(95 \% \mathrm{Cl})\end{array}$ & $\begin{array}{l}\text { Harassment } \\
\text { AOR }(95 \% \mathrm{Cl})\end{array}$ & $\begin{array}{l}\text { Violent relationship } \\
\mathrm{AOR}(95 \% \mathrm{Cl})\end{array}$ \\
\hline $\begin{array}{l}\text { Sexual Identity } \\
\begin{array}{l}\text { Exclusively } \\
\text { Heterosexual }\end{array}\end{array}$ & Referent & Referent & Referent & Referent & Referent & Referent \\
$\begin{array}{l}\text { Mainly Heterosexual } \\
\text { Bisexual }\end{array}$ & $2.51(2.00-3.15)$ & $3.59(2.37-5.42)$ & $1.81(1.47-2.21)$ & $3.32(2.19-5.02)$ & $2.35(1.85-3.00)$ & $3.07(2.43-3.89)$ \\
Lesbian & $2.41(1.41-4.12)$ & $4.74(2.11-10.64)$ & $3.10(1.96-4.90)$ & $5.72(2.68-12.19)$ & $3.30(1.95-5.60)$ & $2.33(1.32-4.13)$ \\
\hline
\end{tabular}

${ }^{\mathrm{a}}$ Education, income and residence

violence-in the main, two to three times greater-in the lives of sexual minority women. This was true for physical abuse (adjusted odds ratios [AOR; odds ratios adjusted for other variables in the model] ranged from 2.14 to 2.51), harassment (AORs ranged from 2.35 to 3.30), and violent relationships (AORs ranged from 1.93 to 3.07). In comparisons of lesbian and exclusively heterosexual women, the only non-significant differences were for emotional abuse and sexual abuse. Conversely, the largest differences were in comparisons of exclusively heterosexual and lesbian women on severe physical abuse $(\mathrm{AOR}=6.40)$ and exclusively heterosexual and bisexual women on sexual abuse $(\mathrm{AOR}=5.72)$. Given the very wide $95 \%$ confidence intervals, these results should be interpreted somewhat cautiously.

\section{Mental health and sexual identity}

Mental health indicators also varied significantly across the sexual identity subgroups. For each of the five indicators (stress, anxiety symptoms, depression, overall mental health, and life satisfaction), mainly heterosexual, bisexual, and lesbian participants scored significantly poorer than did exclusively heterosexual participants. Among the three sexual minority groups, bisexual participants reported the highest levels of stress $(M=1.3$, $\left.S D=.69,\left(\mathrm{~F}_{(3,7587)}=53.0, p<.001\right)\right)$, anxiety symptoms $\left(M=1.7, S D=.99, \mathrm{~F}_{(3,7587)}=23.9, p<.001\right)$ and depression $\left(M=9.5, S D=5.9, \mathrm{~F}_{(3,7487)}=14.9, p<.001\right)$, and the lowest scores on the mental health index $(M=64.1$, $\left.S D=18.4,\left(\mathrm{~F}_{(3,7585)}=17.5, p<.001\right)\right)$ and life satisfaction scale $\left(M=3.0, S D=.51,\left(\mathrm{~F}_{(3,7585)}=33.6, p<.001\right)\right.$.

\section{Interpersonal violence and mental health}

Experiences of interpersonal violence significantly predicted poorer mental health. Women who had experienced any of the six types of interpersonal violence scored significantly higher on stress, anxiety symptoms and depression, and significantly lower on the mental health index and life satisfaction scales. There were moderate positive correlations between the number of types of interpersonal violence and stress $(r=.33$, $p<.001)$, anxiety symptoms $(r=.21, p<.001)$, and depression $(r=.29, p<.001)$, and moderate negative correlations between the number of types of interpersonal violence and the mental health index $(r=-.26, p<.001)$ and life satisfaction scale $(r=-.28, p<.001)$ scores.

Interpersonal violence, mental health, and sexual identity Relationships between the individual types of interpersonal violence experiences, and the number of types of interpersonal violence and poorer mental health varied across sexual identity groups. We fit five linear multiple regression models to the data to systematically examine the relationships among each type of interpersonal violence, sexual identity and mental health (see Table 3 ).

Almost every type of interpersonal violence significantly predicted each of the indicators of mental health. In particular, emotional violence was a strong predictor, with estimated standardized coefficients ranging from Std $\beta=.13,(t=11.1, p<.001)$ to $\operatorname{Std} \beta=.22,(t=16.6$, $p<.001)$. The weakest predictor was severe physical abuse, which significantly predicted higher depression and mental health index scores, with estimated standardized coefficients of Std $\beta=.03,(t=2.53, p<.001)$ and $\operatorname{Std} \beta=.03,(t=2.23, p<.001)$ respectively. Women who identified as mainly heterosexual scored significantly higher on stress, anxiety and depression and significantly lower on the mental health index and the life satisfaction scale. Bisexual identity significantly predicted higher stress and anxiety, and lower life satisfaction scores. Lesbian identity was not a significant predictor of difference in any mental health measure after controlling for level of interpersonal violence.

We fit five additional linear multiple regression models to the data, examining the relationships among the number of types of interpersonal violence experiences, sexual identity, and mental health (also presented in Table 3). The number of types of interpersonal violence was the single strongest predictor of perceived stress $(\operatorname{Std} \beta=.32$, $t=22.5, p<.001)$, anxiety symptoms $(\operatorname{Std} \beta=.19, t=12.4$, $p<.001$ ), depression (Std $\beta=.25, t=17.5, p<.001$ ), poorer overall mental health (Std $\beta=-.24, t=16.1$, $p<.001$ ), and life satisfaction (Std $\beta=-.22, t=13.6$, $p<.001)$. Notably, many of the sexual identity differences in the mental health outcomes found in bivariate analyses were no longer significant once the number of types of 
Table 3 Mental health associations with types of violence and sexual identity, and number of violent experiences and sexual identity, controlling for education, income, and residence in multiple regression models

\begin{tabular}{|c|c|c|c|c|c|c|c|c|c|c|}
\hline & Perceived & Perceived & Anxiety & Anxiety & & & $\begin{array}{l}\text { Mental } \\
\text { health }\end{array}$ & $\begin{array}{l}\text { Mental } \\
\text { health }\end{array}$ & Life & Life \\
\hline & Stress & Stress & Symptoms & Symptoms & CES-D & CES-D & Index & Index & Satisfaction & Satisfaction \\
\hline & M1 & M2 & M3 & M4 & M5 & M6 & M7 & M8 & M9 & M10 \\
\hline & $\operatorname{Std} \beta$ & Std $\beta$ & Std $\beta$ & Std $\beta$ & $\operatorname{std} \beta$ & $\operatorname{std} \beta$ & Std $\beta$ & Std $\beta$ & Std $\beta$ & Std $\beta$ \\
\hline \multicolumn{11}{|l|}{ Type of Violence } \\
\hline Physical abuse & $.08^{* * *}$ & & 0.02 & & $.07^{* * *}$ & & $-.06^{* * *}$ & & $-.05^{* * *}$ & \\
\hline Severe physical abuse & 0.02 & & 0.02 & & $.03 *$ & & $-.03^{*}$ & & -0.01 & \\
\hline Emotional violence & $.22^{* * *}$ & & $.13^{* * *}$ & & $.15^{* * *}$ & & $-.17^{* * *}$ & & $-.16^{* * *}$ & \\
\hline Sexual violence & $.03^{* *}$ & & $.04^{* * *}$ & & 0.02 & & -0.02 & & $-.04 * *$ & \\
\hline Harassment & $.08^{* * *}$ & & $.07^{* * *}$ & & $.07^{* * *}$ & & $-.05^{* * *}$ & & $-.05^{* * *}$ & \\
\hline In a violent relationship & $.06^{* * *}$ & & $.05^{* * *}$ & & $.03^{*}$ & & $-.03^{*}$ & & -0.02 & \\
\hline Number of Violent Experiences & & $.324^{* * *}$ & & $.194^{* * *}$ & & $.251^{* * *}$ & & $-.240^{* * *}$ & & $-.223^{* * *}$ \\
\hline \multicolumn{11}{|l|}{ Sexual Identity } \\
\hline Exclusively heterosexual & Referent & Referent & Referent & Referent & Referent & Referent & Referent & Referent & Referent & Referent \\
\hline Mainly heterosexual & $.06^{* * *}$ & $.06^{* * *}$ & $.06^{* * *}$ & $.06^{* * *}$ & $.03^{*}$ & $.03^{*}$ & $-.05^{* * *}$ & $-.05^{* * *}$ & $.06^{* * *}$ & $.06^{* * *}$ \\
\hline Bisexual & $.06^{* * *}$ & $.06^{* * *}$ & $.04^{* *}$ & $.04^{* * *}$ & 0.02 & 0.02 & -0.02 & -0.02 & $-.03^{*}$ & $-.03^{*}$ \\
\hline Lesbian & .01 & .01 & .02 & .01 & .01 & .01 & -.01 & -.01 & -.01 & -.01 \\
\hline
\end{tabular}

interpersonal violence was included in the models. Identifying as lesbian was not a significant predictor of any mental health outcome. Bisexual identity was significantly associated with three mental health outcomes: perceived stress (Std $\beta=.06, t=5.27, p<.01$ ), anxiety symptoms (Std $\beta=.04, t=3.27, p<.001$ ), and life satisfaction (Std $\beta=-.22, t=2.34, p<.05)$. Of particular note is the fact that mainly heterosexual self-identity remained a significant predictor of every mental health outcome. Specifically, mainly heterosexual identity predicted higher perceived stress (Std $\beta=.06, t=5.39, p<.001$ ), greater anxiety symptoms (Std $\beta=.06 t=4.97, p<.001$ ), higher level of depression (Std $\beta=.03, t=2.28, p<.05$ ), poorer overall mental health (Std $\beta=-.05, t=3.80, p<.001)$, and lower life satisfaction (Std $\beta=-.06, t=5.27, p<.001$ ).

\section{Discussion}

These findings from a population-based national sample contribute to the growing body of evidence supporting the disproportionate burden of interpersonal violence on sexual minority women $[10,14,16,27,40]$. Such findings are consistent with minority stress theory which attributes sexual-orientation-related mental health disparities to societal and contextual factors [41]. Further, variations in prevalence of interpersonal violence across sexual minority subgroups point to the need for additional research aimed at greater understanding of within-group differences.

Results of the study support our first hypothesis that, relative to exclusively heterosexual women, sexual minority women (mainly heterosexual, bisexual, and lesbian) would be at heightened risk of interpersonal violence, and that experiences of violence would differ across sexual minority subgroups. Indeed, sexual minority women in the study were more likely to report every type of interpersonal violence assessed in the study. Some of this difference may be attributed to the increased vulnerability to interpersonal violence that comes with visibility as a sexual minority person $[40,42,43]$. Researchers have found that sexual minority individuals who are more open about their sexual orientation (i.e., more visible) are more likely to experience victimization $[24,44]$. Lesbian women are more likely than bisexual, and presumably more likely than mainly heterosexual women, to disclose their sexual identity-a factor that may explain, at least in part, lesbians' higher rates of some types of interpersonal violence [45]. However, this does not explain higher rates of some types of interpersonal violence amongst bisexual and mainly heterosexual women, whose sexual orientation is less publicly visible.

Although we were unable to ascertain the sex of perpetrators of partner violence, it is reasonable to speculate that bisexual and mainly heterosexual women are more likely than lesbian women to have been in recent (past three years) violent relationships with male partners. Findings in the literature, however, suggest that partner violence may occur at the same rate in opposite- and samesex couples; or, in same-sex male couples, at higher rates $[19,46,47]$. Therefore, factors in addition to partner sex likely influence risk of interpersonal violence among sexual minority women. Because mainly heterosexual and bisexual women are on the whole less likely to be affiliated with 
lesbian communities and may also feel alienated from the heterosexual community, they may experience heightened feelings of isolation and loneliness that contribute to risk of IPV and to negative mental health outcomes [29, 48]. In addition, as discussed in the background section, mainly heterosexual women are at heightened risk of alcohol and other drug use, which may render them more vulnerable to violence. Additional research examining sexual identity subgroup differences in health behaviors and health outcomes is needed to more fully understand these relationships.

In regard to hypothesis 2 that experiences of violence would predict poorer mental health we found that the number of types of violence was the strongest predictor of mental health and that this association held even when controlling for demographic characteristics and sexual identity. These findings suggest that interpersonal violence is a robust predictor of poor mental health, regardless of sexual identity. In addition, the absence of a significant interaction effect of sexual identity on the relationship between interpersonal violence and mental health suggests that the effects of interpersonal violence do not differ substantially by sexual identity. Interpersonal violence contributes to poor mental health among all women.

As a caveat to the findings indicating a strong relationship between interpersonal violence and poor mental health, we found that even after controlling for interpersonal violence, mainly heterosexual women reported higher levels of stress, anxiety, and depression, and lower overall mental health and life satisfaction. The standardized coefficients for the effect of mainly heterosexual identity ranged from .03 to .06 , whereas the standardized coefficients for the effect of interpersonal violence ranged from .19 to .32. This was also true, to a lesser degree, for bisexual women who, after controlling for interpersonal violence in the models, reported higher levels of stress and anxiety, and lower life satisfaction. These findings suggest that there exists a complex array of influences on sexual minority women's mental health, including marginalization and lower levels of social connectedness, which are likely more pronounced among bisexual and mainly heterosexual women than among lesbian women.

Our findings are consistent with a those from a growing number of studies showing that women who identify as mainly heterosexual are at increased risk of poor mental health $[10,16,49,50]$. In previous analyses of young women in the ALSWH, mainly heterosexual women were more likely than exclusively heterosexual and lesbian women to report self-harm and feeling that life was not worth living [16]. Results of those analyses also indicated that mainly heterosexual women had lower levels of social support than did exclusively heterosexual or lesbian women. Similarly, Corliss and colleagues found that mostly heterosexual women were less likely to report social support from friends and family and more likely to report a history of and treatment for depression [49]. The lower levels of social support found in these studies lends evidence to the supposition that mainly heterosexual women are even more likely than other sexual minority groups to be marginalized and isolated, and that these experiences likely contribute to heightened risk of adverse health outcomes.

\section{Strengths and limitations}

This study has a number of important strengths. The sample was recruited without explicit sexual orientation criteria. The data are from a national sample, rather than being defined by a region or occupational group, and thus includes women that represent a wide range of geographic, socioeconomic, and personal circumstances. The large sample size afforded the opportunity to examine differences across sexual minority subgroups. Sexual minority subgroup sample sizes, to our knowledge, are among the largest of any national sample. (The National Epidemiologic Survey on Alcohol and Related Conditions [NESARC], conducted in the United States, has comparable numbers of lesbian and bisexual women.) In addition, whereas most studies, particularly most national studies (including the NESARC), assess sexual identity based on a three-category response option (lesbian, bisexual, heterosexual), the question used in the current study allowed women to choose from a wider range of sexual identity response options. Our findings, as well as those from other studies indicating heightened risk among mostly heterosexual women, point to the importance of including this group in studies aimed at understanding health disparities among sexual minorities [10, 16, 22, 37, 49, 51].

Finally, most of the measures were well established scales (e.g., CES-D) or have been validated in previous waves of the ALSWH.

Despite these strengths, several limitations should be considered when interpreting the findings. First, the response rate of the original survey of the young cohort was low $(40 \%-41 \%$ for the baseline and $68 \%$ and $64 \%$ of the baseline at the second and third follow-up surveys). Additionally, 2.4\% $(n=211)$ of participants did not respond to the question regarding their sexual orientation (i.e., they indicated that they were unsure of their sexual identity or they refused to answer the question). Each of these factors could limit the generalizability of the findings. It is important to note, however, that Powers and Loxton's examination of the impact of attrition in the ALSWH concluded that the biases were insufficient to preclude meaningful longitudinal analyses [52]. Second, although sexual identity was assessed, other major sexual orientation dimensions, such as sexual attraction and behavior, were not. Having information about sexual attraction and sexual behavior would have permitted more nuanced assessments of sexual orientation-related mental health risks and could 
have been used to better understand how women in the study self-identified-information that would have been particularly helpful in understanding the women who identified as mainly heterosexual.

The current study was conducted using cross sectional data, so no inferences as to causation can be made. For example, although it is possible that emotional abuse leads to poor mental health outcomes, it is also possible that poor mental health might lead to heightened perceptions or reporting of emotional abuse.

Harassment experiences are likely related, at least in part, to sexual orientation discrimination; however, given the wording of the question, we were unable to distinguish the perceived causes of harassment. Similarly, the study is limited by the lack of information regarding the gender of perpetrators of interpersonal violence.

Finally, there are likely other important variables (e.g., heavy drinking or drug use) not included in the analyses that are associated with both victimization and mental health.

\section{Conclusions}

Given that sexual minority women are at higher risk of interpersonal violence and poor mental health outcomes, violence prevention and mental health services targeting women with diverse sexual identities are crucial. Our findings highlight sexual-orientation-related disparities in experiences of interpersonal violence and point to important subgroup differences that go beyond a binary categorization of sexual orientation. In addition, study findings lend evidence to the assertion that social and contextual factors such as interpersonal violence, rather than sexual minority status, accounts for some of the mental health disparities observed among sexual minority women. The growing body of findings indicating heightened risk of adverse mental health outcomes among mainly heterosexual women suggests that this subgroup may have additional risk factors not assessed in this study. The wellbeing of women who identify as mainly heterosexual warrants further research to better understand women who choose this identity category and the factors that contribute to their heightened risk of violence and poor mental health. Although the health impact of interpersonal violence on women in the general population is increasingly acknowledged and taken into account in clinical practice, mental health referral pathways for sexual minority women are less clear. In particular, research has found that clinicians tend to assume that same-sex partnered women are at low or no risk of intimate partner violence [53]. To more fully understand sexual-orientation-related mental health disparities, additional research is needed that addresses risk behaviors, relationship characteristics, and other psychosocial factors associated with women's diverse sexual identities.

\section{Endnotes}

${ }^{1}$ Same-sex couples are prevented from marrying in Australia. Same-sex unions are treated as de facto unions under the Australian federal law, though each Australian state and territory is entitled to create their own laws with respect to same-sex relationship registers and same-sex partnership schemes.

\section{Abbreviations \\ ALSWH: Australian Longitudinal Study on Women's Health; CES-D: Center for Epidemiologic Studies Depression Scale; CPA: Childhood physical abuse; CSA: Childhood sexual abuse; LGB: Lesbian, Gay and Bisexual; NESARC: The National Epidemiologic Survey on Alcohol and Related Conditions; SF-36: Medical Outcomes 36-item Short Form Survey}

\section{Acknowledgements}

The research on which this manuscript is based was conducted as part of the Australian Longitudinal Study on Women's Health by the University of Queensland and the University of Newcastle. We are grateful to the Australian Government Department of Health for funding and to the women who provided the survey data.

Funding

This manuscript was funded by the Gay and Lesbian Medical Association's Lesbian Health Fund in the United States. The Australian Longitudinal Study on Women's Health is funded by the Australian Government Department of Health.

Availability of data and materials

Public Use data sets are available at: www.alswh.org.au

\section{Authors' contributions}

LAS made substantial contributions to conception and design, conducted the data analysis, and interpretation of data; drafted and edited the manuscript, and gave final approval of the version to be published; TLH made substantial contributions to conception and design, interpretation of data; drafted and edited the manuscript, made substantial edits in revision, and gave final approval of the version to be published; RM made substantial contributions to conception and design, interpretation of data; drafted and edited the manuscript, made substantial edits in revision, and gave final approval of the version to be published; DL made substantial contributions to conception and design, interpretation of data; drafted and edited the manuscript, made substantial edits in revision, and gave final approval of the version to be published.

\section{Ethics approval and consent to participate}

This study protocol was approved by the University of Newcastle's Human Research Ethics Committee, approval no's. H-076-0795 and H-2012-0256, and the University of Queensland's Medical Research Ethics Committee, approval no's. $2,004,000,224$ and $2,012,000,950$

\section{Consent for publication}

Not applicable.

\section{Competing interests}

The authors declare that they have no competing interests.

\section{Publisher's Note}

Springer Nature remains neutral with regard to jurisdictional claims in published maps and institutional affiliations.

\section{Author details}

${ }^{1}$ Office of Nursing Research, College of Nursing, University of Arizona, Tucson, USA. ${ }^{2}$ Nursing and Psychiatry, School of Nursing, Columbia University, New York City, USA. ${ }^{3}$ Global Health Research, School of Nursing, Columbia University, New York City, USA. ${ }^{4}$ Department of General Practice, The University of Melbourne, Melbourne, Australia. ${ }^{5}$ Australian Longitudinal Study on Women's Health, University of Newcastle, Melbourne, Australia.

${ }^{6}$ Research Centre for Generational Health and Ageing, University of Newcastle, Callaghan, Australia. 
Received: 31 August 2016 Accepted: 20 September 2017 Published online: 30 September 2017

\section{References}

1. World Health Organization. (2002). World report on violence and health, Geneva: Author.

2. Mouzos J, Makkai T. Women's experiences of male violence: Findings from the Australian component of the International Violence Against Women Survey. In: Research and Public Policy Series no. 56. Canberra: Author: Australian Institute of Criminology; 2004.

3. VicHealth. The health costs of violence: Measuring the burden of disease caused by intimate partner violence. In: A summary of findings. Melbourne: Victorian Health Promotion Foundation; 2004.

4. Coker AL, Davis KE, Arias I, Desai S, Sanderson M, Brandt HM, et al. Physical and mental health effects of intimate partner violence for men and women. Am J Prev Med. 2002;23(4):260-8.

5. Gatz M, Russell LA, Grady J, Kram-Fernansez D, Clark C, Marshall B. Women's recollections of victimization, psychological problems, and substance use. J Com Psychol. 2005;33(4):479-93.

6. Becker M, Noether C, Larson M, Gatz M, Brown V, Heckman J, et al. Characteristics of women engaged in treatment for trauma and co-occurring disorders: Findings from a national multisite study. J Com Psychol. 2005;33(4):429-43.

7. Golding J. Intimate partner violence as a risk factor for mental disorders: A meta-analysis. J Fam Violence. 1999;14:99-132.

8. Helfrich CA, Fujiura GT, Rutkowski-Kmitta V. Mental health disorders and functioning of women in domestic violence shelters. J Interpers Violence. 2008;23(4):437-53.

9. Mullen PE, Romans-Clarkson SE, Walton VA, Herbison GP. Impact of sexual and physical abuse on women's mental health. Lancet. 1988;1:841-5.

10. Hughes TL, McCabe SE, Wilsnack SC, West BT, Boyd CJ. Violence and substance use disorders in a national sample of heterosexual and sexual minority women and men. Addiction. 2010;105(12):2130-40. doi:10.1111/j. 1360-0443.2010.03088x.

11. Hughes TL, Johnson TP, Steffan A, Wilsnack SC, Everett B. Lifetime victimization, hazardous drinking and depression among heterosexual and sexual minority women. LGBT Health. 2014;1(3):1-12.

12. Loxton D, Schofield M, Hussain R. Psychological health in midlife among women who have ever lived with a violent partner or spouse. J Interpers Violence. 2006:21:1092-107.

13. Maclsaac MB, Bugeja LC, Jelinek GA. The association between exposure to interpersonal violence and suicide among women: a systematic review. Aust N Z J Public Health. 2017;41(1):61-9. doi:10.1111/1753-6405.12594.

14. Hughes TL, Johnson TP, Wilsnack SC. Sexual assault and alcohol abuse: A comparison of lesbians and heterosexual women. J Subst Abus. 2001;13(4):515-32.

15. Bostwick WB, Boyd CJ, Hughes T, McCabe S. Dimensions of sexual orientation and the prevalence of mood and anxiety disorders in the United States. Am J Public Health. 2010;100(3):468-75.

16. Hughes TL, Szalacha LA, McNair R. Substance abuse and mental health disparities: Comparisons across sexual identity groups in a national sample of young Australian women. Soc Sci Med. 2010;71(4):824-31.

17. Cochran SD, Sullivan JG, Mays VM. Prevalence of mental disorders, psychological distress, and mental health services use among lesbian, gay, and bisexual adults in the United States. J Consult Clin Psychol. 2003;71(1):53-61

18. Austin SB, Jun HJ, Jackson B, Spiegelman D, Rich-Edwards J, Corliss HL, et al. Disparities in child abuse violence in lesbian, bisexual, and heterosexual women in the Nurses' Health Study II. J Women's Health. 2008;17(4):597-606.

19. Balsam KF, Rothblum ED, Beauchaine TP. Violence over the life span: A comparison of lesbian, gay, bisexual, and heterosexual siblings. J Consult Clin Psychol. 2005;73(3):477.

20. Stoddard JP, Dibble SL, Fineman N. Sexual and physical abuse: A comparison between lesbians and their heterosexual sisters. J Homosex. 2009:56(4):407-20.

21. Descamps MJ, Rothblum E, Bradford J, Ryan C. Mental health impact of child sexual abuse, rape, intimate partner violence, and hate crimes in the national lesbian health care survey. J Gay \& Lesbian Soc Serv. 2000;11(1):27-55.

22. Hughes TL, Szalacha LA, Johnson TP, Kinnison KE, Wilsnack SC, Cho Y. Sexual violence and hazardous drinking among heterosexual and sexual minority women. Addict Behav. 2010;35:1152-6.

23. Austin SB, Roberts AL, Corliss HL, Molnar BE. Sexual violence history and sexual risk indicators in a community-based urban cohort of "mostly heterosexual" and heterosexual young women. Am J Public Health. 2008;98(6):1015.
24. D'Augelli AR, Grossman AH. Disclosure of sexual orientation, violence, and mental health among lesbian, gay, and bisexual older adults. J Interpers Violence. 2001;16(10):1008-27.

25. Heidt JM, Marx BP, Gold SD. Sexual re-violence among sexual minorities: A preliminary study. J Trauma Stress. 2005;18(5):533-40.

26. Morris JF, Balsam KF. Lesbian and bisexual women's experiences of violence: Mental health, re-violence, and sexual identity development. J Lesbian Stud. 2003;7(4):67-85.

27. Moracco KE, Runyan CW, Bowling JM, Earp JAL. Women's experiences with violence: A national study. Womens Health Issues. 2007;17(1):3-12.

28. Drabble L, Trocki KF, Hughes TL, Korcha RA, Lown AE. Sexual orientation differences in the relationship between victimization and hazardous drinking among women in the National Alcohol Survey. Psychol Addict Behav. 2013;27(3):639-48.

29. Hughes TL, Wilsnack SC, Kristjanson A. Substance use and related problems among U.S. women who identify as mostly heterosexual. BMC Public Health. 2015;15:803.

30. Lee C, Dobson AJ, Brown WJ, Bryson L, Byles J, Warner-Smith P, et al. Cohort profile: The Australian Longitudinal Study on Women's Health. Int J Epidemiol. 2005;34(5):987-91.

31. Dobson AJ, Hockey R, Brown WJ, Byles JE, Loxton DJ, McLaughlin DP, Tooth LR, Mishra GD. Cohort profile update: Australian Longitudinal Study on Women's Health. Int J Epidemiol. 2015; https://doi.org/10.1093/ije/dyv110.

32. Brown WJ, Bryson L, Byles JE, Dobson AJ, Lee C, Mishra G, et al. Women's Health Australia: Recruitment for a national longitudinal cohort study. Women's Health. 1998:28(1):23-40.

33. Hegarty K, Valpied J. Composite abuse scale manual. Melbourne: Department of General Practice, University of Melbourne; 2007.

34. Bell S, Lee C. Development of the perceived stress questionnaire for young women. Psychol Health Med. 2002;7(2):189-201.

35. Bell S, Lee C. Perceived stress revisited: the Women's Health Australia project Younger cohort. Psychol Health Med. 2003;8(3):343-53.

36. Andersen EM, Malmgren JA, Carter WB, Patrick DL. Screening for depression in well older adults: evaluation of a short form of the CES-D (Center for Epidemiologic Studies Depression Scale). Am J Prev Med. 1994:10:77-84.

37. McHorney CA, Ware JE Jr, Lu JF, Sherbourne CD. The MOS 36-item ShortForm Health Survey (SF-36): III. Tests of data quality, scaling assumptions, and reliability across diverse patient groups. Med Care. 1994;32:40-66.

38. Australian Government Department of Health. Australian Longitudinal Study of Women's Health. http://www.alswh.org.au/for-researchers/surveys.

39. StataCorp. 2013. Stata Statistical Software: Release 13. College Station, TX: StataCorp LP

40. Wilsnack SC, Hughes TL, Johnson TL, Bostwick WB, Szalacha LA, Benson PB, Aranda FA, Kinnison KE. Drinking and drinking-related problems among heterosexual and sexual minority women. J Stud Alcohol Drugs. 2008;69(1):129-39.

41. Meyer $\mathbb{H}$. Prejudice, Social Stress, and Mental Health in Lesbian, Gay, and Bisexual Populations: Conceptual Issues and Research Evidence. Psychol Bull. 2003:129(5):674-97.

42. Herek GM. Confronting sexual stigma and prejudice: Theory and practice. J Soc Issues. 2007:63:905-25.

43. Herek GM. Sexual stigma and sexual prejudice in the United States: A conceptual framework. In: Hope DA, editor. Contemporary perspectives on lesbian, gay \& bisexual identities: The 54th Nebraska Symposium on Motivation. New York: Springer; 2009. p. 65-111.

44. Huebner DM, Rebchook GM, Kegeles SM. Experiences of harassment, discrimination, and physical violence among young gay and bisexual men. Am J Public Health. 2004:94:1200-3.

45. Gates GJ. Sexual minorities in the 2008 General Social Survey: Coming out and demographic characteristics. Los Angeles, CA: The Williams Institute UCLA; 2010.

46. Lehavot K, Simoni JM. The impact of minority stress on mental health and substance use among sexual minority women. J Consult Clin Psychol. 2011; 79(2):159-70.

47. Messinger AM. Invisible Victims: Same-Sex IPV in the National Violence Against Women Survey. J Interpers Violence. 2011;26:2228-43.

48. Lhomond B, Saurel-Cubizolles MJ. Violence against women and suicide risk: The neglected impact of same-sex sexual behaviour. Soc Sci Med. 2006;62(8):2002-13.

49. Corliss HL, Austin SB, Roberts AL, Molnar BE. Sexual risk in "mostly heterosexual" young women: Influence of social support and caregiver mental health. J Women's Health. 2009;18(12):2005-10. 
50. Ziyadeh N, Prokop LA, Fisher LB, Rosario M, Field AE, Camargo CA Jr, et al. Sexual orientation, gender, and alcohol use in a cohort study of US adolescent girls and boys. Drug Alcohol Depend. 2007:87:119-30.

51. Murray CE, Mobley AK, Buford AP, Seaman-DeJohn MM. Same-sex intimate partner violence: Dynamics, social context, and counseling implications. J LGBT Issues Couns. 2006/2007;1(4):7-30.

52. Powers J, Loxton D. The Impact of Attrition in an 11-Year Prospective Longitudinal Study of Younger Women. Annu Epidemiol. 2010;20:318-21.

53. Ard KL, Makadon HJ. Addressing intimate partner violence in lesbian, gay, bisexual, and transgender patients. J Gen Intern Med. 2011;26(8):930-3.

Submit your next manuscript to BioMed Central and we will help you at every step:

- We accept pre-submission inquiries

- Our selector tool helps you to find the most relevant journal

- We provide round the clock customer support

- Convenient online submission

- Thorough peer review

- Inclusion in PubMed and all major indexing services

- Maximum visibility for your research

Submit your manuscript at www.biomedcentral.com/submit
Biomed Central 